\title{
Análise comparativa do efeito térmico e do desgaste sofrido por um material de fricção de freio a disco submetido a ensaios em bancada Krauss com variações de potência motora e condições operacionais.
}

\section{Comparative analysis of the thermal effect and wear suffered by a disc brake friction material subjected to Krauss bench tests with engine power variations and operating conditions.}

Rafael Lucas Machado Pinto ${ }^{1}$, Juan Carlos Horta Gutiérrez ${ }^{1}$, Rodrigo Cardoso Menezes ${ }^{1}$, Juan Carlos Campos Rubio ${ }^{1}$, Paulo Eustáquio Faria ${ }^{1}$

\footnotetext{
${ }^{1}$ Universidade Federal de Minas Gerais - Av. Antônio Carlos, 6.627, CEP: 31270-901, Belo Horizonte, MG, Brasil. e-mail: rafaelucas@gmail.com, horta@demec.ufmg.br, menezes.eng@hotmail.com,juan@demec.ufmg.br, paulofaria@ eng-mec.dout.ufmg.br
}

\begin{abstract}
RESUMO
Estudo que visa à análise comparativa dos efeitos térmicos e do desgaste sofridos pelo par tribológico de um sistema de freio durante ensaios realizados variando a potência motora de um banco de ensaio de freios. Como é conhecido, o mecanismo de freio é empregado para controlar a velocidade convertendo energia cinética e/ou energia potencial em energia térmica. Neste estudo, objetivou-se analisar os parâmetros de operação de um sistema de freio a disco para motocicletas utilizando-se um banco de ensaios baseado no procedimento Krauss, descrito pela norma ABNT NBR 6143/1995. Os ensaios experimentais foram conduzidos em duas etapas. Na primeira, o banco de ensaios foi equipado com um motor de $3 \mathrm{cv}$ de potência motora e utilizou-se um planejamento fatorial $2^{3}$, em que os três fatores de controle considerados foram alterados deliberadamente em dois níveis cada. Para avaliar o desempenho do sistema de freio durante o processo de frenagem, analisaram-se três variáveis de resposta simultaneamente: temperatura final, coeficiente de atrito e desgaste das pastilhas de freio. Na segunda etapa, a potência motora foi aumentada para 10cv; analisou-se o efeito dos fatores pressão de contato e velocidade de escorregamento, que foram alterados em quatro níveis cada. Aqui foi analisada a variável de resposta desgaste das pastilhas de freio. Como resultado da análise comparativa realizada, foi possível constatar que os ensaios da segunda etapa mostraram um maior desgaste e aquecimento do material de atrito do mecanismo de freio estudado, o que promoveu redução do coeficiente de atrito em função do aumento da temperatura, especialmente acima de $300^{\circ} \mathrm{C}$, fenômeno este conhecido na literatura como efeito fade de frenagem.
\end{abstract}

Palavras-chave: Sistema de freios, atrito, efeitos térmicos, desgaste, fade.

\begin{abstract}
Study aiming at comparative analysis of the thermal effects and wear suffered by the tribological pair of a brake system during tests performed by varying the motor power of a brake test bench. As is known, the brake mechanism is employed to control speed by converting kinetic energy and/or potential energy into thermal energy. This study aimed to analyze the operating parameters of a motorcycle disc brake system using a test bench based on the Krauss procedure, described by ABNT NBR 6143/1995. Experimental tests were conducted in two steps. In the first one, the test bench was equipped with a $3 \mathrm{hp}$ engine of motor power and a $2^{3}$ factorial design was used, in which the three control factors considered were deliberately changed at two levels each. To evaluate the performance of the brake system during the braking process, three response variables were analyzed simultaneously: final temperature, friction coefficient and brake pad wear. In the second stage, the
\end{abstract}


motor power was increased to $10 \mathrm{hp}$; The effect of contact pressure and sliding velocity factors, which were changed at four levels each, was analyzed. Here the brake pad wear response variable was analyzed. As a result of the comparative analysis, it was found that the tests of the second stage showed greater wear and heating of the friction material of the studied brake mechanism, which promoted a reduction of the coefficient of friction as a function of temperature increase, especially above $300^{\circ} \mathrm{C}$, a phenomenon known in the literature as the braking fade effect.

Keywords: System of brakes, friction, thermal effects, wear, fade.

\section{INTRODUÇÃO}

O sistema de freio é um dispositivo empregado para controlar a velocidade de um veículo ou máquina, convertendo a energia cinética e/ou a energia potencial em energia térmica. O princípio básico envolvido é o atrito. Xiao et al. (2016) [1] ressaltam que freio por atrito tem sido amplamente usados em vários equipamentos de transporte e tráfego, como automóveis, trens, aviões, e dispositivos industriais (elevadores, guindastes de mineração, etc).

O componente que mais influencia no desempenho de um sistema de freio a disco é a pastilha, que é fabricada com materiais de fricção. Para otimizar o processo de frenagem, os fabricantes estudam as variáveis que influenciam as propriedades destes materiais. Os principais equipamentos utilizados para se estudar essas variáveis são: o dinamômetro inercial, Chase, Fast e Krauss.

De acordo com Limpert (2011) [2] e Brembo (1997) [3], pastilhas de freio são compósitos formados pela compactação de 10 a 20 materiais diferentes, que podem ser classificados em quatro grupos básicos: fibras, cargas, aglutinantes e modificadores de atrito.

De acordo com Xiao et al. (2016) [1] os materiais de atrito de freio podem ser classificados, de acordo com a matriz material, como metálicos, semi-metálicos e não metálicos. Já Kruze (2009) [4] cita que os materiais de fricção para freios veiculares são divididos em dois grupos: orgânicos e semi-metálicos. Os materiais orgânicos, devido à proibição quanto ao uso de asbesto, passaram a ser denominados no asbestos organic (NAO). Os principais constituintes deste tipo de material de fricção são: resinas, materiais orgânicos e inorgânicos, grafite, mica, fibras metálicas (em baixo percentual) e de aramida, responsável pela substituição do amianto. Já os materiais semi-metálicos apresentam uma carga maior de compostos metálicos (fibras de aço) em sua constituição, podendo chegar a 50\% do material de formulação. Birch (1999) [5] realizou uma comparação entre os materiais orgânicos e semi-metálicos, obtendo as seguintes conclusões: materiais orgânicos apresentam menor custo, são menos abrasivos, o que gera menor desgaste do disco de freio, baixo ruído, bom coeficiente de atrito a frio e são mais sensíveis ao efeito fade; já materiais semi-metálicos são mais caros, frágeis, apresentam baixo coeficiente de atrito a frio, são mais resistentes ao efeito fade e possuem maior vida útil.

De acordo com Limpert (2011) [2], um veículo mantém-se conectado à estrada devido às forças de tração produzidas pelos pneus. Todas as forças de frenagem, direção ou aceleraração devem ser geradas pela área do pneu em contato com a superfície da estrada. Somente forças iguais ou menores que o produto da força normal pelo coeficiente de atrito entre o pneu e a estrada podem ser transmitidas pelos pneus e rodas. Mesmo o sistema ideal de frenagem não pode utilizar mais tração que a provida entre pneus e estrada.

Segundo Infantini (2008) [6] os parâmetros a serem considerados para avaliar o desempenho de materiais de fricção veicular são o coeficiente de atrito e o desgaste. Sanders et al. (2001) [7] enfatizam que o coeficiente de atrito depende principalmente das seguintes variáveis: velocidade de escorregamento, pressão de contato e temperatura na interface do par de friç̧ão. A velocidade de escorregamento e a pressão de contato podem ser diretamente controladas na máquina de ensaio, diferentemente da temperatura, que é consequência destes parâmetros, bem como das características mecânicas e térmicas do sistema. Segundo Xiao et al. (2016) [1], as pesquisas existentes focam principalmente nestes três fatores.

De acordo com Infantini (2008) [6], a velocidade de escorregamento tem efeito pouco significativo sobre o desempenho dos sistemas de freio. Em função da geometria da pastilha de freio em sistemas a disco, há uma variação da velocidade tangencial de escorregamento ao longo do seu raio. Brezolin (2007) [8] menciona que a pressão de contato é influenciada pelo desgaste, geometria da pastilha de freio, posição do pistão de freio em relação à pastilha, deformações da pastilha e do disco de freio e pela carga imposta ao sistema pelo condutor do veículo através da pressão hidráulica do sistema. De acordo com Xiao el al. (2016) [1], a pressão de frenagem afeta o atrito e o desgaste através do tamanho e deformação da área de contato real. De acordo com a tribologia moderna, a força de atrito depende do tamanho da área de contato real. O número e o tamanho dos pontos de contato aumentarão com o aumento da pressão de frenagem. Se o contato entre a interface for plástico, o coeficiente de friç̧ão será independente da pressão de frenagem. No entanto, o contato é realmente elástico-plástico. Além disso, a pressão de frenagem também afetará outros fatores, como temperatura e lubrificação. Uma vez que a área de contato real não é proporcional à pressão de frenagem, o coeficiente de atrito não é proporcional à pressão de frenagem.

De acordo com Montgomery (2012) [9], experimentos são realizados por pesquisadores em praticamente todos os campos de investigação, usualmente para descobrir algo sobre um processo ou sistema em particular. Experimentos 
planejados são empregados com o objetivo de obter melhoria de um determinado processo. A ferramenta DOE (Design of Experiments) é uma técnica estatística utilizada para planejar, conduzir e analisar os resultados de um experimento, a fim de validar uma determinada proposição para a solução de um problema. Consiste de séries de execuções, ou testes, nos quais mudanças intencionais são feitas simultaneamente para variáveis de um processo, e os efeitos são observados nas variáveis resposta.

Segundo Sousa et. al. (2012) [10] diversas áreas do conhecimento utilizam ferramentas de análise estatística para investigar hipóteses propostas. Uma das maneiras de se realizar esta análise se dá através de técnicas de comparação múltipla entre as médias de tratamentos experimentais. Esta técnica é realizada posteriormente à ANOVA. De acordo com Walpole et al. (2009) [11], a ANOVA é um procedimento poderoso para testar a homogeneidade de um conjunto de médias. Entretanto, ao rejeitar a hipótese nula e aceitar a hipótese alternativa - de que as médias são iguais - ainda não é possível saber quais dentre as médias populacionais são iguais e quais são diferentes. Suponha que, seguindo uma ANOVA em que se rejeita a hipótese nula de igualdade de médias de tratamentos, deseja-se testar todas as comparações pareadas entre médias. Uma das técnicas estatísticas de comparação múltipla amplamente utilizadas para este objetivo foi proposto por Tukey, que define um procedimento para testar essas hipóteses e construir intervalos de confiança para as médias que controla a taxa de erro global no nível de significância selecionado.

No presente artigo, foi utilizado um banco de ensaios elaborado a partir do procedimento de Krauss, regido pela norma ABNT NBR 6143/1995 [12]. Optou-se por realizar experimentos utilizando-se 3 fatores operacionais do sistema de freio e 2 valores distintos de potência motora, com o objetivo de analisar a aplicação de um mesmo sistema de freio sob diferentes potências, bem como verificar os efeitos térmicos e tribológicos provocados neste sistema de freio estudado. Além disso, têm-se o objetivo de ilustrar o surgimento do efeito fade em condições operacionais onde o sistema de frenagem alcança temperaturas mais elevadas. Os primeiros ensaios, conduzidos utilizando-se um motor de $3 \mathrm{cv}$ de potência, foi executado conforme Planejamento de Experimento Fatorial $2^{3}$, em que as três variáveis de entrada relacionadas ao processo de frenagem de motocicletas (disco, pastilha e pressão de acionamento da manete de freio) foram manipulados em 2 níveis cada. Foram realizadas análises estatísticas deste experimento, utilizando-se gráficos fatorais, análise de variância (ANOVA) e o teste de Tukey para as variáveis resposta temperatura, coeficiente de atrito e desgaste das pastilhas de freio. Em seguida, foram conduzidos experimentos onde a bancada foi acionada por meio de um motor de $10 \mathrm{cv}$ de potência. Para esta nova configuração, foram analisados os efeitos dos fatores velocidade de escorregamento e pressão de contato em relação à resposta desgaste. Desta forma, tornou-se possível analisar as variáveis significativas no estudo, em relação à variáveis resposta consideradas, contribuindo para compreender o comportamento deste importante dispositivo veicular.

\section{MATERIAIS E MÉTODOS}

\subsection{Descrição do banco de ensaios}

A Figura 1 representa, esquematicamente, a bancada de ensaios desenvolvida para este estudo. O banco de ensaios foi equipado, na primeira etapa dos experimentos, com um motor de $3 \mathrm{cv}$ de potência e, na segunda, com um motor de $10 \mathrm{cv}$. Conta um inversor de frequência para controle da velocidade de rotação do motor e a transmissão mecânica é obtida por meio de um sistema de polias e correias. É equipado com sensores de temperatura, velocidade e de momento da força de força de frenagem, que por meio de um sistema de aquisição de dados permite a comunicação com um computador. 


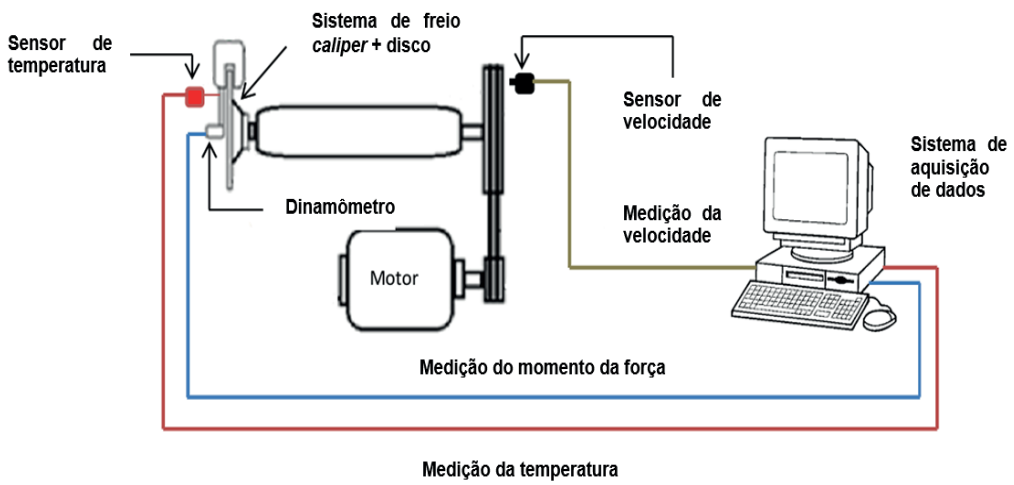

Figura 1: Representação esquemática do banco de ensaios

Os testes foram realizados por meio do procedimento de Krauss, descito pela norma ABNT NBR 6143/1995 [12]. A força de frenagem foi obtida por meio de um dinamômetro, representado pela Figura 2-a, baseado no princípio de funcionamento de uma alavanca. A medição da força produzida por este sistema de alavanca ocorreu através da utilização de uma célula de carga da marca Eletronic Scale, que possui capacidade de até $392 \mathrm{~N}$ e resolução de $0,024 \mathrm{~N}$. Adotando-se $F_{t}$ como a força tangencial que atua sobre o ponto de tomada de medição, em [N] e $r_{a}$ o comprimento da alavanca, em [m], torna-se possível calcular o momento da força de frenagem, em [N.m], através da relação expressa pela Equação 1:

$$
M_{t}=F_{t} \cdot r_{a}
$$

O monitoramento da velocidade de rotação do eixo que contém o disco ocorreu através de um tacogerador eletrônico da marca Cycle Computer. Já a temperatura do disco foi medida empregando-se um pirômetro digital infravermelho da marca Infrared Thermometer. As medições são realizadas na região do disco imediatamente posterior ao contato com as pastilha, conforme pode ser observado na Figura 2-b.
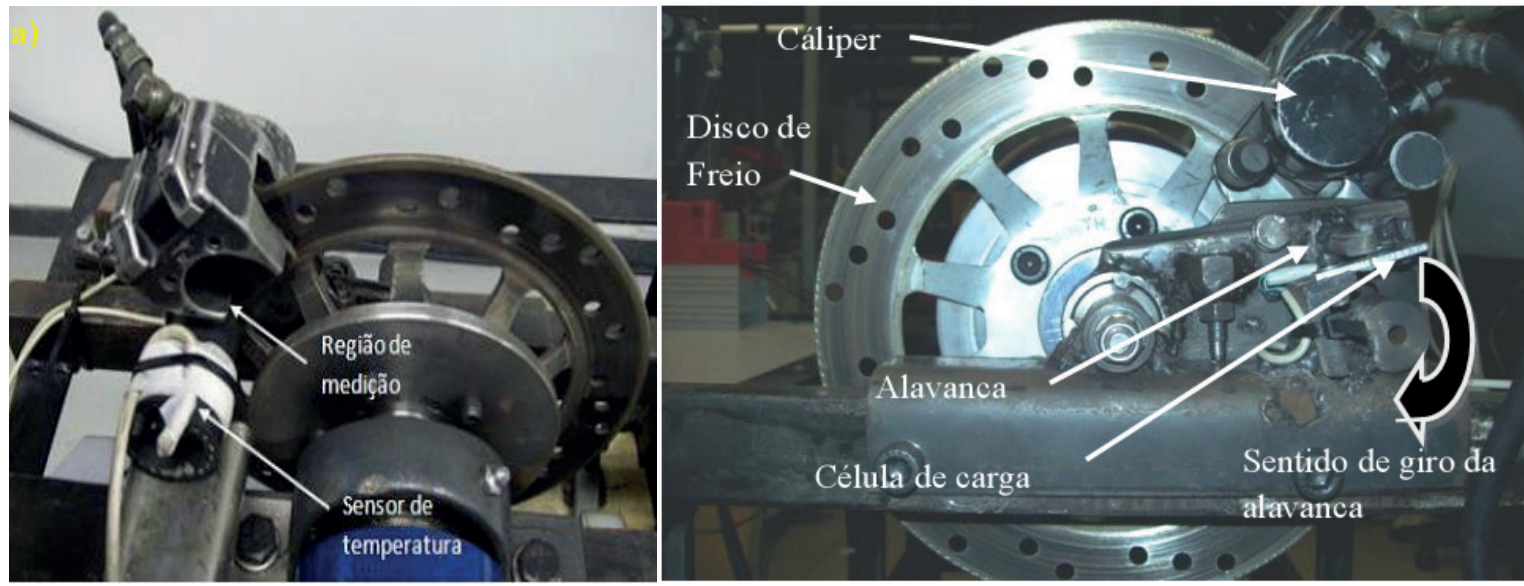

Figura 2: a) mecanismo para obtenção da força tangencial; b) região de medição da temperatura.

\subsection{Metodologia de condução dos experimentos}

A norma ABNT NBR 6143/1995 [12] define alguns procedimentos para execução dos ensaios de frenagem segundo a metodologia de Krauss. O primeiro deles está relacionado à duração de cada frenagem, que deve ser de 5 segundos. Concluída uma frenagem, deve-se aguardar um tempo de 10 segundos até a execução da próxima aplicação do freio. A norma estabelece o conceito de ciclos de frenagens, que representam um conjunto de frenagens consecutivas, sendo que cada ciclo é constituído por 10 frenagens. O ensaio total é composto por 10 ciclos de frenagens. Desta forma, um conjunto de 100 frenagens são realizados em um experimento completo.

Inicia-se o ensaio com o disco à temperatura ambiente ou à existente no mesmo, desde que inferior a $50^{\circ} \mathrm{C}$. Já os demais ciclos somente podem ser iniciados quando a temperatura for inferior a $100^{\circ} \mathrm{C}$. Os três primeiros ciclos são conduzidos para garantir assentamento das superfícies de trabalho. Os ciclos 4 a 10 somente são executados quando há um assentamento mínimo de $80 \%$ de entre o par de atrito. Estes são os sete ciclos de frenagens considerados para analisar os ensaios realizados. 
Uma das variáveis respostas analisadas como resultado dos ensaios é o coeficiente de atrito entre o par de atrito pastilha-disco. Adotando-se $M t$ como o momento da força de frenagem, em [N.m], $r_{e}$ como o raio efetivo do disco, em [m], $P_{h}$ a pressão hidrálica na linha de fluido do freio, em [Pa], $A_{p}$ a área da pastilha, em [m²], a norma ABNT NBR 6143/1993 [12] propõe o cálculo do coeficiente de atrito através da Equação 2:

$$
\mu=M_{t} /\left(2 \cdot r_{e} \cdot A_{p} \cdot P_{h}\right)
$$

O valor da pressão hidráulica na linha de fluido de freio foi obtida por meio da relação de alavanca entre as dimensões dos braços de força e de resistência da manete de freio, considerando-se a pressão pneumática para acionamento da manete, o raio do pistão do atuador pneumático, o raio do pistão da pinça e o raio do cilindro mestre do freio.

\subsection{Fatores e respostas analisadas}

A primeira etapa do experimento, onde o banco de ensaios foi equipado com um motor de $3 \mathrm{cv}$, foi realizado segundo um Planejamento Fatorial $2^{3}$, em que as 3 variáveis consideradas foram manipuladas em dois níveis cada. Para as variáveis tipo de disco e tipo de pastilha, definiu-se como nível baixo (-1) discos e pastilhas que já foram submetidos a cinco ensaios completos de frenagens, denominados "meia-vida". Já materiais novos configuram o nível alto $(+1)$ destes dois fatores. Busca-se, através do estudo destes dois fatores, analisar se há diferenças de desempenho nas propriedades térmicas e tribológicas do sistema de freio quanto ao nível de assentamento no par tribológico (materiais em estado meia-vida possuem assentamento superior entre as superfícies de contato que promovem a frenagem). Todos os discos de freios utilizados eram de ferro fundido cinzento e as pastilhas do tipo orgânica. Já para o fator pressão de acionamento da manete de freio foi definidos o nível alto $50 \%$ superior em relação ao nível baixo. O objetivo desta variação dos níveis do fator pressão é analisar se o esforço feito pelo condutor para acionar o sistema de freio influencia nas propriedades térmicas e tribológicas do sistema de freio. Tabela 1 ilustra cada variável considerada neste estudo. Para cada combinação entre os níveis dos três fatores, foram consideradas sete réplicas, equivalentes aos ciclos de frenagem 4 a 10, conforme descrito no tópico 2.2. O software Minitab 17 foi utilizado para planejamento experimental e para obtenção dos resultados provenientes das técnicas estatísticas aplicadas a partir dos dados coletados.

Tabela 1: Níveis dos fatores Controláveis.

\begin{tabular}{c|c|c}
\hline Fatores Controláveis & Nível -1 & Nível +1 \\
\hline X1: Tipo de Disco & Meia-vida & Novo \\
\hline X2: Tipo de Pastilha & Meia-vida & $0,15 \mathrm{MPa}$ \\
\hline X3: Valor da Pressão & $0,10 \mathrm{MPa}$ & \\
\hline
\end{tabular}

Foram consideradas 3 variáveis resposta: coeficiente de atrito, temperatura final em cada frenagem e o desgaste sofrido pelas pastilhas de freio ao longo das frenagens. Para o coeficiente de atrito, por se tratar de uma resposta cuja função objetivo é de maximização, quanto maiores forem os seus valores melhor, uma vez que proporcionam maior efetividade durante a frenagem. Para a temperatura final, por ser uma resposta com função objetivo de minimização, quanto menor o seu valor melhor, uma vez que o sistema de freio fica menos sujeito a perdas de eficiência devido a efeitos térmicos, como, por exemplo, o fade. O desgaste também é uma variável resposta cuja função objetivo é de minimização. O desgaste das pastilhas foi obtido através da subtração entre as medições das espessuras das pastilhas antes e após o ensaio. Utilizou-se um micrômetro com resolução de $0,01 \mathrm{~mm}$ para se realizar tais medições.

Já a segunda etapa do experimento teve por objetivo analisar a variável resposta desgaste das pastilhas ao submeter o experimento a um nível de potência mais elevado. Para tanto, substituiu-se o motor de $3 \mathrm{cv}$ por um motor de $10 \mathrm{cv}$. Fixou-se o uso de pastilhas e discos novos para estes experimentos. Foram utilizados 4 níveis para cada fator, conforme Tabela 2. Utilizou-se ANOVA e Teste Tukey para analisar estes novos resultados obtidos.

Tabela 2: Níveis dos fatores Controláveis.

\begin{tabular}{l|l|l|l|l}
\hline \multicolumn{1}{c|}{ Fatores Controláveis } & \multicolumn{3}{c}{ Níveis } \\
\hline X1: Velocidade de Escorregamento [m/s] & 5,00 & 6,00 & 7,00 & 8,00 \\
\hline X2: Pressão de Contato $[\mathrm{MPa}]$ & 0,67 & 1,34 & 2,00 & 2,67 \\
\hline
\end{tabular}




\section{RESULTADOS}

\subsection{Análise das variáveis resposta Coeficiente de atrito e Temperatura}

Utilizou-se a metodologia estatística planejamento fatorial completo $2^{3}$ do software Minitab 17 para gerar o experimento e analisar os dados coletados. Utilizou-se a técnica de Análise de Variância (ANOVA), que testa a hipótese de que as médias de duas ou mais populações são iguais. Análises ANOVA testam a importância de um ou mais fatores comparando as médias das variáveis de resposta em diferentes níveis dos fatores. De acordo com Minitab (2019) [13] a técnica busca testar, para cada fator ou interação entre os fatores, as seguintes hipótese:

$\mathrm{H}_{0}$ : As médias dos níveis dos fatores ou das interações são iguais.

$\mathrm{H}_{1}$ : Pelo menos uma das médias dos níveis dos fatores ou das interações é diferente das demais.

Ainda de acordo com Minitab (2019) [13], quando o p-valor associado a cada teste for menor que o nível de significância considerado, rejeita-se a hipótese nula de que as médias dos níveis dos fatores produzem efeitos iguais na variável resposta considerada. Logo, neste caso, o fator ou a interação entre os fatores é considerada significativa, pois diferentes níveis promovem diferenças significativas na variável resposta. A Tabela 3 apresenta os p-valores provenientes da ANOVA para as três variáveis resposta estudadas.

Para a variável resposta Temperatura Final, nota-se que, ao nível de significância $\alpha=0,05$, somente as interação entre os fatores disco e pastilha, disco e pressão e a interação dos três fatores simultaneamante não causam alterações médias significativas nesta variável resposta. Todos os demais fatores e interações promovem modificações consideráveis.

Análise semelhante pode ser realizada para o coeficiente de atrito, em que somente as interações disco e pastilha e dos três fatores atuando simultaneamente não promovem mudanças significativas médias na variável resposta coeficiente de atrito.

Tabela 3: P-valores ANOVA para as variáveis respostas

\begin{tabular}{l|c|c|c}
\hline \multicolumn{1}{c|}{ Resposta } & Temp. Final & Coef. de atrito & Desgaste \\
Componente & & 0,000 & 0,082 \\
\hline Disco & 0,000 & 0,000 & 0,104 \\
\hline Pastilha & 0,022 & 0,003 & 0,444 \\
\hline Pressão & 0,000 & 0,479 & 0,564 \\
\hline Disco*Pastilha & 0,056 & 0,007 & 0,261 \\
\hline Disco*Pressão & 0,128 & 0,023 & 0,529 \\
\hline Pastilha*Pressão & 0,001 & 0,772 & 0,053 \\
\hline Disco*Pastilha*Pressão & 0,094 & & \\
\hline
\end{tabular}

Já para o desgaste das pastilhas, os resultados indicam que não há diferença entre os níveis de cada fator ou de interações em promover alterações significativas nesta variável resposta. Por exemplo, o p-valor associado ao tipo de disco foi 0,082 . Ao nível significância adotado, $\alpha=0,05$, os níveis baixos (disco "meia-vida") e alto (disco novo) não apresentaram diferenças significativas quanto aos desgastes observados. Resultado semelhante ocorreu para o intervalo de valores ensaios para a pressão de acionamento do freio. Como o p-valor associado ao efeito da pressão no desgaste foi de 0,444 , variando-se o valor da pressão de 0,10 para $0,15 \mathrm{MPa}$, não se observou variações significativas no desgaste das pastilhas.

\subsection{Análise Gráfica da Temperatura e Coeficiente de Atrito}

A Figura 3-a representa o gráfico de cubo para a variável resposta coeficiente de atrito. Cada vértice deste cubo equivale aos valores médios desta variável para as combinações dos tratamentos dos três fatores, cada um em dois níveis.

Quanto maior o valor médio da resposta coeficiente de atrito durante uma frenagem melhor é, pois alcança-se uma maior efetividade durante a frenagem. Desta forma, o maior valor observado foi no vértice do cubo que representa os três fatores em seus níveis mais baixos (disco e pastilhas "meia-vida" e pressão de acionamento 0,10 MPa), cujo valor foi 0,37824. Entretanto, considerando os tratamentos com disco e pastilhas "meia-vida", o fator pressão de acionamento não 
apresenta muita influência no coeficiente de atrito, sendo que em seu nível alto $(0,15 \mathrm{MPa})$ o valor da variável resposta coeficiente de atrito é 0,36766

a) Gráfico de cubo para o Coeficiente de Atrito

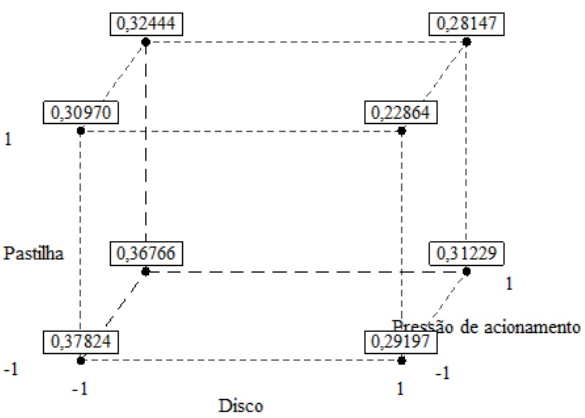

b)

Gráfico de Cubo para a Temperatura Final

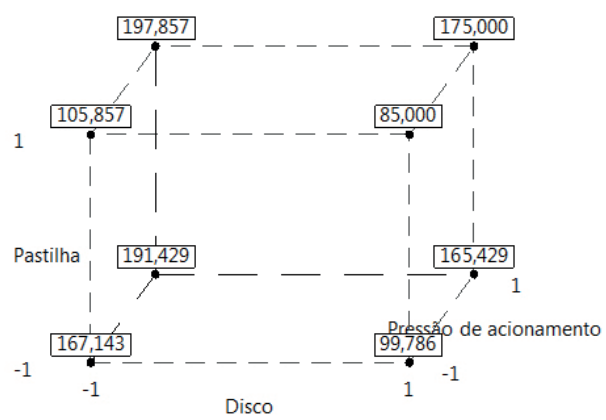

Figura 3: a) Gráfico de Cubo para a variável resposta coeficiente de atrito; b) Gráfico de Cubo para a variável resposta Temperatura Final.

Já a Figura 3-b representa o gráfico de cubo para a variável resposta Temperatura. Quanto menor o valor da temperatura experimentado por um sistema de freio durante uma frenagem melhor é, pois desta forma o sistema fica menos sujeito a efeitos térmicos, como decaimento do coeficiente de atrito (efeito fade), comportamento não constante entre frenagens seguintes e trincas térmicas. Desta forma, o menor valor observado foi no vértice do cubo que representa o tratamento com disco de freio novo, pastilhas novas e pressão de acionamento de $0,10 \mathrm{MPa}$, cujo valor foi de $85^{\circ} \mathrm{C}$. A explicação para o comportamento do coeficiente de atrito e da temperatura em relação aos tipos de pastilha e disco pode ser feita através do entendimento da área de contato real do par de atrito. Pastilhas e discos "meia-vida" apresentam uma maior área de contato real, o que causa aumento no coeficiente de atrito. Consequentemente, a temperatura também aumenta nesta situação. Além disso, segundo Horta Gutiérrez et al. (2013) [14], pastilhas que apresentam elementos abrasivos mais degastados estão sujeitas a uma ação predominante do atrito entre os elementos e não a de cisalhamento por parte dos grãos abrasivos sobre o material do disco. Consequentemente, pastilhas "meia-vida" aquecem mais e apresentam maiores valores de coeficiente de atrito.

\subsection{Análise da Variável Resposta desgaste das pastilhas - Potência motora de 3cv}

Conforme demonstrado por meio da Tabela 3, os p-valores ANOVA provenientes da variável resposta desgaste das pastilhas de freios para cada fator ou interação entre os fatores foram todos acima do nível de significância considerado. Desta forma, conforme procedimento de interpretação dos resultados obtidos através do software Minitab 17, diferentes níveis dos fatores não promovem alterações significativas consideráveis para o desgaste. A Figura 4 representa o gráfico de efeitos principais para esta variável resposta. Ela possui função objetivo de minimização, pois quanto menor for o desgaste sofrido pelo material de atrito com o passar do tempo melhor, em função de maior durabilidade e redução de custos com substituições. Por mais que este gráfico nos indique que os níveis altos do disco e pastilhas (ambos novos) e a pressão no nível baixo $(0,1 \mathrm{MPa})$ forneça uma combinação de menos desgaste das pastilhas, ao nível de significância $\alpha=0,05$ não é possível concluir que existe diferenças estatisticamente significativas no desgaste quando se altera tais níveis. Tais resultados também podem ser observados através do teste de Tukey. De acordo com Minitab (2019) [13], o gráfico de intervalo de confiança de Tukey é o melhor gráfico para ser usado para determinar os intervalos prováveis das diferenças e para avaliar a significância prática dessas diferenças. 


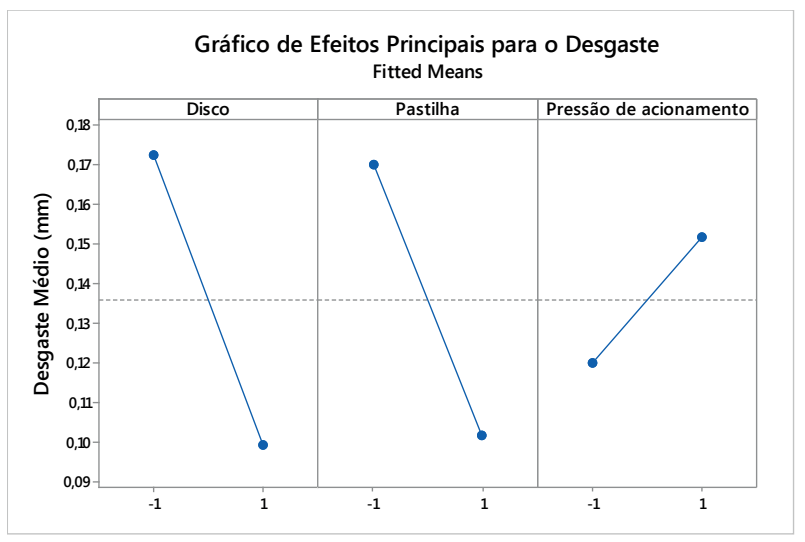

Figura 4: Gráfico de efeitos principais para a variável resposta Desgaste das Pastilhas de Freio - potência $3 \mathrm{cv}$

A Figura 5 representa a saída do software Minitab 17 para o teste Tukey referente ao fator disco de freio. Segundo Walpole et al. (2009) [11] o procedimento de Tukey permite a formação de intervalos de confiança 100(1- $\alpha) \%$ simultâneos para todas as comparações em pares. O método é baseado em uma distribuição da estatística de amplitude estudentizada. $\mathrm{O}$ percentil apropriado é uma função de $\alpha, \mathrm{k}$ e v= graus de liberdade para $\mathrm{S}^{2}$. Ainda de acordo com os referidos autores, o método de comparações em pares de Tukey envolve a descoberta de uma diferença de significância entre as médias i e j, se exceder q[ $\alpha, k, v]$.Pelo critério utilizado, sugerido pelo Minitab (2019) [13] se o intervalo entre os níveis do fator conter o zero, significa que aqueles níveis não apresentam diferenças significativas capazes de alterar a variável resposta, no nível de significância considerado. Analisando-se esta Figura, nota-se que o intervalo relativo aos níveis alto e baixo contém o zero, o que significa dizer que as médias dos dois níveis considerados não são significativamente diferentes, para $\alpha=0,05$.

Resultados semelhantes foram obtidos para os fatores pastilha e pressão de acionamento da manete de freio, representados pela Figuras 6. Para estes, os intervalos referente aos níveis altos e baixos também contém o zero, não podendo-se considerar que há diferenças significativas entre estes níveis capazes de promover diferenças no desgaste das pastilhas, ao nível de significância adotado neste estudo. Tais resultados obtidos coincidem com os obtidos na ANOVA.

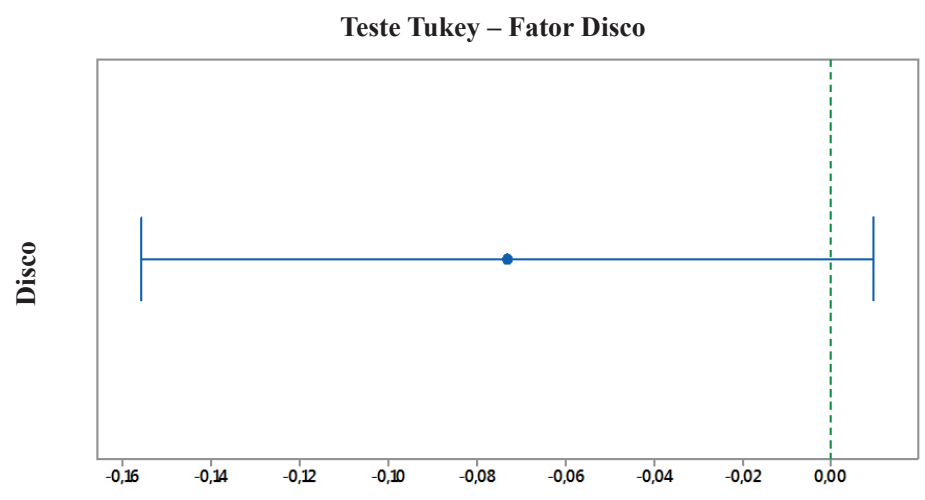

Figura 5: Teste Tukey para o fator disco

a)

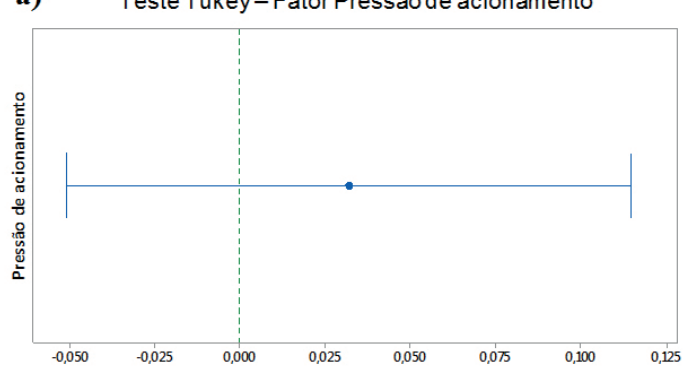

b)

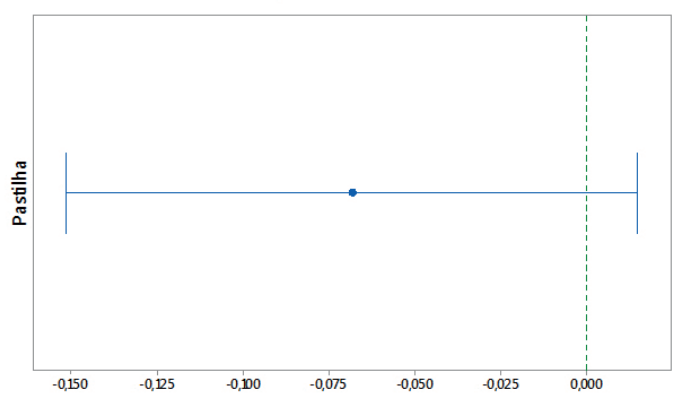

Figura 6: a)Teste Tukey para o fator pressão de acionamento; b)Teste Tukey para o fator pastilha 


\subsection{Análise do Desgaste para ensaios com potência motora de $10 \mathrm{cv}$}

A mudança da potência motora de 3 para $10 \mathrm{cv}$ tem por objetivo analisar o comportamento da variável resposta desgaste quando o sistema de freio precisa converter uma maior quantidade de energia cinética para promover a frenagem, convertendo-a em energia térmica.

Para este experimento, buscou-se analisar o efeito da velocidade de escorregamento, que é a variação tangencial da velocidade de escorregamento ao longo da direção radial, e da pressão de contato na interface do par tribológico em relação à variável resposta desgaste das pastilhas de freio. Sanders et. al. (2001) [7], salienta que o coeficiente de atrito e o desgaste dependem da velocidade de escorregamento, da pressão de contato e da temperatura na interface do par tribológico.

A Figura 7-a ilustra o gráfico de Efeitos Principais para a variável resposta desgaste. Percebe-se um aumento do desgaste à medida que há um aumento tantos nos níveis da velocidade de escorregamento, quanto da pressão de contato. Para o fator velocidade de escorregamento, os três níveis mais baixos ensaiados $(5,6$ e $7 \mathrm{~m} / \mathrm{s})$, apresentaram menores valores de desgaste, que tornou-se mais significativo no nível mais altos $(8 \mathrm{~m} / \mathrm{s})$. Tais resultados coincidem com os encontrados por Deng et at. (2010) [15], que também observaram um aumento da taxa de desgaste com o aumento da velocidade. Para a pressão de contato, os resultados encontrados coincidem com os obtidos por Wang et al. (2008) [16] e Bao et al. (2012) [17], que observaram aumento da taxa de desgaste de pastilhas de freio com o aumento da pressão de contato. O P-valor ANOVA para o fator velocidade de escorregamento foi 0,002, enquanto que para a Pressão de Contato foi 0,000. Considerando-se o mesmo nível de significância para os ensaios conduzidos com potência motora de $3 \mathrm{cv}$, conclui-se que tanto o fator velocidade de escorregamento quanto a pressão de contato podem ser considerados significativos, ou seja, pelo menos uma das médias dos níveis destes fatores é diferente das demais.

Como cada fator foi manipulado em 4 níveis, seria importante identificar qual (ou quais) destes níveis promovem diferenças significativas, ao nível de significância estatística considerado. Pela análise de variância, apenas é possível saber que pelo um dos níveis de cada fator é diferente dos demais, não sendo possível identificar quais deles são diferentes entre si. Para isto, será utilizado o Teste Tukey.

A Figura 7-b representa a saída do software Minitab 17 para o teste Tukey referente à variável de entrada velocidade de escorregamento. Pelo critério utilizado, se o intervalo entre os níveis do fator conter o zero, significa que aqueles níveis não apresentam diferenças significativas capazes de alterar a variável resposta, no nível de significância considerado. Analisando-se esta figura, nota-se que os intervalos para as velocidades de escorregamento (6-5; 7-5; e 7-6 m/s) contém o zero, o que significa dizer que estes três níveis não promovem diferenças significativas na variável resposta desgaste, para $\alpha=0,05$. Já os intervalos de velocidade de escorregamento $(8-5 ; 8-6$ e 8-7m/s) não contém o zero, o que significa que, para o mesmo nível de significância utilizado, existem diferenças estatisticamente consideráveis, em relação ao desgaste, entre a velocidade de escorregamento 8m/s para as demais. Através da Figura 7-a é possível observar tal fenômeno, onde o maior "salto" da curva de desgaste ocorre da velocidade $7 \mathrm{~m} / \mathrm{s}$ para a velocidade $8 \mathrm{~m} / \mathrm{s}$, quando seu valor aumenta consideravelmente.

Procedimento semelhante, ilustrado pela Figura 8-a, foi empregado para o fator pressão de contato. Analisando-se esta figura, nota-se que os intervalos para os valores de pressão de contato (1,34-0,67; 2,00-1,34 MPa) contém o zero, o que significa dizer que entre os níveis de pressão de contato 1,34 e 0,67 MPa; 2,00 e 1,34 MPa não há diferenças significativas em relação ao comportamento da variável resposta desgaste, para $\alpha=0,05$. Já os intervalos de velocidade de escorregamento $(2,00-0,67 ; 2,67-0,67 ; 2,67-1,34 ; 2,67-2,00 \mathrm{MPa})$ não contém o zero, o que significa que, para o mesmo nível de significância utilizado, existem diferenças estatisticamente consideráveis, em relação ao desgaste, entre estes níveis do fator pressão de contato pareado. Por exemplo, ensaios conduzidos com pressão de contato de 2,00 MPa promovem desgaste na pastilha diferentes, e com maiores valores (conforme pode ser observado na Figura 7-a em relação aos realizados com pressão de contato de $0,67 \mathrm{MPa}$.

a)

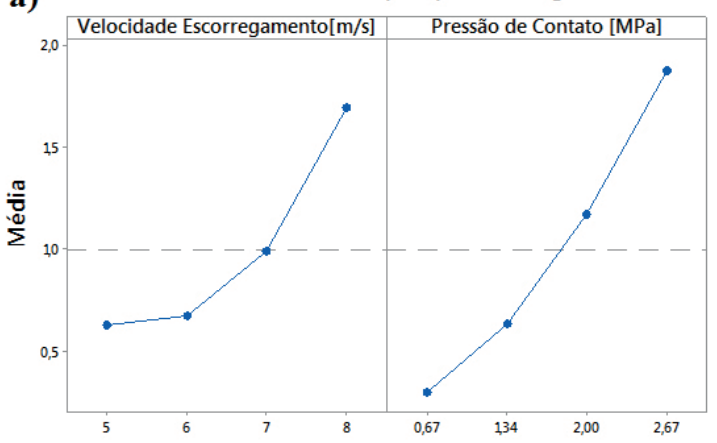

b) Teste Tukey - Fator velocidade de escorregamento

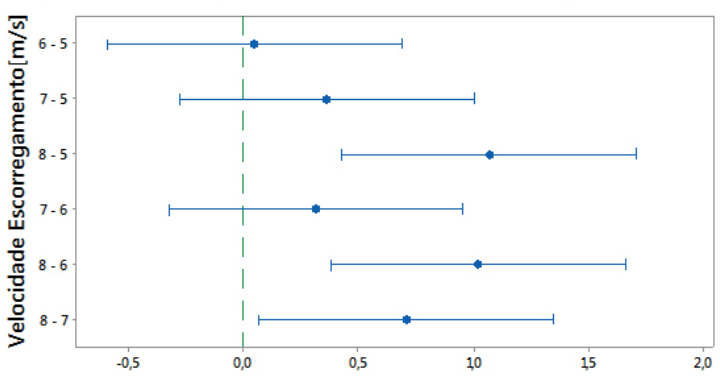

Figura 7: a) Gráfico de efeitos principais para a variável resposta Desgaste das Pastilhas de Freio - potência $10 \mathrm{cv}$; b) Teste Tukey para o fator velocidade de escorregamento 


\subsection{Identificação do efeito fade no experimento com potência motora de $10 \mathrm{cv}$}

Em função dos experimentos da segunda etapa terem sido executados com um nível de potência mais do que triplicada, observou-se maiores valores de temperatura nestes ensaios, em função do sistema de freio precisar converter uma maior quantidade de energia cinética em energia térmica para promover a frenagem. Quando um sistema de freio por atrito fica submetido a temperaturas mais elevadas, ocorre um fenômeno de redução do coeficiente de atrito, denominado efeito fade. Limpert (2011) [2], ressalta que este efeito é mais reduzido em freios a disco do que em freios a tambor. Trata-se de um efeito extremamente indesejável, mas presente, durante a frenagem, pois ocorre redução da eficiência do sistema de freio do veículo. Nos ensaios da primeira etapa, o fade não foi observado, pois a temperatura máxima alcançado durante um experimento não ultrapassou $250^{\circ} \mathrm{C}$. Já para ensaios da segunda etapa, o fade se manifestou, conforme pode ser observado na Figura 8-b.

Por meio da Figura 8-b, que representa um experimento utilizando-se pastilhas e discos novos, com os fatores velocidade de escorregamento e pressão de contato em seus níveis mais elevados, observa-se que o coeficiente de atrito vai crescendo no início deste ciclo de frenagem, atinge um valor máximo entre a quinta e sexta frenagem (para um valor de temperatura na casa de $450^{\circ} \mathrm{C}$ ) e, a partir deste ponto, o valor do coeficiente de atrito cai consideravelmente. Esta significativa redução do coeficiente de atrito com aumento da temperatura evidencia o efeito fade neste processo. De acordo com Limpert (2011) [2] e Osterle et al. (2009) [18], este efeito pode ser atribuído às transformações químicas que geralmente ocorrem em condições de mais altas temperaturas (degradação da resina fenólica e queima de materiais voláteis) presentes no material de formulação da pastilha de freio.

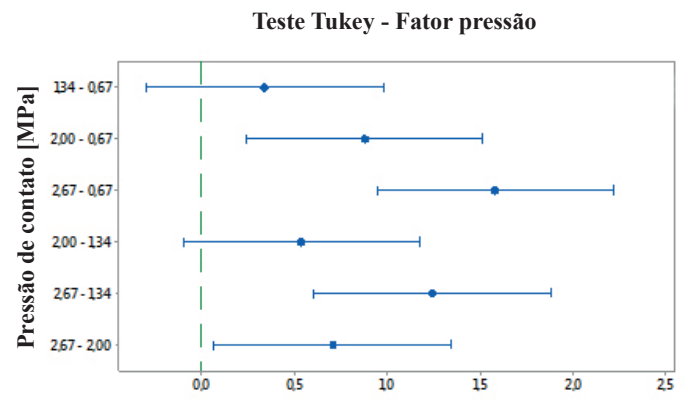

a)

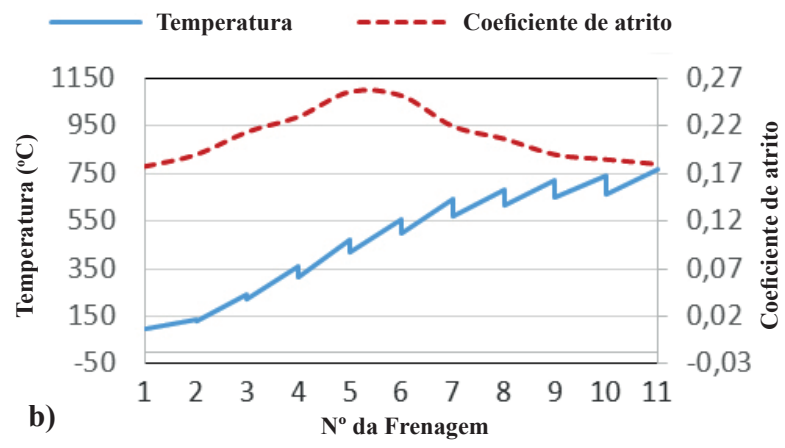

Figura 8: a) Teste Tukey para o fator pressão de contato; b) Coeficiente de atrito e temperatura - pastilha nova, disco novo, $\mathrm{P}=10 \mathrm{cv}$,

\section{CONCLUSÕES}

No experimento estudado, a primeira etapa foi estruturada através de um Planejamento Fatorial $2^{3}$, em que três fatores relacionados à operação de um sistema de frenagem de uma motocicleta de baixa cilindrada, que são os tipos de disco, pastilhas e pressão de acionamento da manete de freio, foram manipulados em dois níveis cada. Foram analisados os comportamentos das três variáveis resposta do modelo fatorial utilizado através da análise de variância, gráficos fatoriais, como o gráfico de cubo e efeitos principais, a partir de dados coletados de um banco de ensaios dimensionado para esta finalidade. A partir desta análise, tornou-se possível identificar os melhores níveis de cada fator que otimizam cada variável resposta separadamente. Para a temperatura, a melhor combinação foi disco e pastilhas novos, pressão de com disco de freio novo e pressão de contato de 0,10 MPa. Para o coeficiente de atrito, foram os três fatores em seus níveis mais baixos (disco e pastilhas "meia-vida" e pressão de acionamento $0,10 \mathrm{MPa}$ ). Já para o desgaste das pastilhas, observou-se que os fatores analisados não promoveram alterações significativas, ao nível de significância considerado $(\alpha=0,05)$, nesta resposta. Este último resultado também foi demonstrado via teste de Tukey. O resultados obtidos são válidos para os intervalos de valores dos fatores utilizados neste experimento, não sendo possível realizar extrapolações para valores fora destes intervalos.

Por fim, o banco de ensaios foi equipado com uma potência motora mais elevada $(10 \mathrm{cv})$, com o intuito de investigar o efeito dos fatores velocidade de escorregamento e pressão de contato na variável resposta desgaste das pastilhas de freio. Por meio desta nova configuração experimental, pode-se identificar que ambas variáveis analisadas promoveram desgastes estatisticamente significativos ao alterar seus níveis controláveis. A configuração que mais promoveu o desgaste das pastilhas foi para os níveis mais elevados de velocidade de escorregamento e pressão de contato. Juntamente com a técnica ANOVA empregada, foi aplicado o Teste de Tukey. Através desta ferramenta, foi possível identificar quais níveis dos fatores apresentaram comportamentos iguais, ou diferentes, quanto ao desgaste promovido nas pastilhas de freio. Desta forma, a identificação dos melhores níveis de operação dos fatores possibilita a escolha daqueles que minimizam o desgaste das 
pastilhas de freio, resultando em redução de custos de manutenção e substituições de componentes. Foi observado, também, que os ensaios da segunda etapa alcançaram maiores níveis de temperatura, em função do incremento de potência, ficando mais suscetível ao efeito fade.

Para trabalhos futuros, sugere-se a aplicação de técnicas de otimização global, capazes de identificar os melhores níveis dos fatores que otimizam múltiplas variáveis resposta simultaneamente.

\section{BIBLIOGRAFIA}

[1] XIAO, X., YIN, Y., BAO, J., FEN, X., "Review on the friction and wear of brake materials". Advances in Mechanical Engeneering 2016, Vol. 8 (5) 1-10, Sage, 2016.

[2] LIMPERT, R. Brake Design and Safety, $3^{\text {rd }}$ ed., SAE, 2011.

[3] BREMBO, S.P.A.,The Brake Disc Manual, 1 ed., Manual, Curno, 128p, 1997

[4] KRUZE, G. A. S. Avaliação do Coeficiente de Atrito em um Dinamômetro em Escala Reduzida. Dissertação de Mestrado - Programa de Pós-Graduação em Engenharia Mecânica, Universidade Federal do Rio Grande do Sul, Porto Alegre, RS, 2009

[5] BIRCH, T.W. Automotive Braking Systems, Third edition, Delmar, 1999.

[6] INFANTINI, M. B. Variáveis de Desempenho dos Sistemas de Freio. (Dissertação de Mestrado em Engenharia Mecânica). Escola de Engenharia - Programa de Pós-Graduação em Engenharia Mecânica - Universidade Federal do Rio Grande do Sul, Porto Alegre - RS, Brasil, 2008

[7] SANDERS, P.G., DALKA, T.M., BASH, R.H. "A Reduced-Scale Brake Dynamometer for Friction Characterization". Tribology International, vol. 34, pp. 609-615, 2001.

[8] BREZOLIN, A. Estudo de Geração de Trincas Térmicas em Discos de Freios de Veículos Comerciais. (Dissertação de mestrado em Materiais), Programa de Pós-Graduação em Engenharia e Ciência dos Materiais, Universidade de Caxias do Sul, Caxias do Sul, 2007.

[9] MONTGOMERY, D.C. Introduction to Statistical Quality Control, 7 ed., John Wiley\& Sons, Inc., 2012.

[10] SOUSA, C. A., JUNIOR, M. A. L., FERREIRA, R. L. C. "Avaliação de testes estatísticos de comparações múltiplas de médias”, Revista Ceres, Vol. 59 n. 3 Viçosa. Maio/Junho de 2012.

[11] WALPOLE, R. E., MYERS, R.H., MYERS, S. L., et al. Probabilidade e Estatística para engenharia e ciências. [Tradução Vianna, L. F. P.]. São Paulo: Pearson Prentice Hall, 2009.

[12] ASSOCIAÇÃO BRASILEIRA DE NORMAS TÉCNICAS, Rio de Janeiro NBR 6143:1995 - Pastilha do Freio a disco - Determinação do atrito e desgaste através da bancada de ensaio Krauss.

[13] MINITAB (2019). Site de suporte do software. Disponível em: $<$ http://support.minitab.com/pt-br/minitab/17/topic-library/modeling statistics/anova/basics/what-is-anova/>. Acessado em 29 de janeiro de 2019

[14] HORTA GUTIÉRREZ, J.C., ABREU, R.M, VASCONCELOS, I.R., et al. "Estudo Experimental do Desempenho de Sistema de Freio Automotivo". CIBIM, La Plata, 2013.

[15] DENG, H., LI, K., LI, H., et al. "Effect of brake pressure and brake speed on the tribological properties of carbon/ carbon composites with diferente pyrocarbon textures". Wear, v.270, pp. 95-103, 2010

[16] WANG, L., LI, Y., GUO, X. H., et al. "Study on friction and wear property of train powder metallurgy brake disc". Locomotive and Rolling Stock Technol, v.5, pp.27-28, 2008.

[17] BAO, J. S., ZHU, Z. C., TONG, M. M., et al. "Influence of braking pressure on tribological performance of non-asbestos brake shoe for mine hoister during emergency braking”. Ind Lubr Tribol, v.64, pp.230-236, 2012.

[18] OSTERLE, W., DORFEL, I., PRIETZEL, C., et al. "A comprehensive microscopy study of third body formation at the interface between a brake pad na brake disc during the final stage of a pin-on-disc test". Wear, v.267, pp.781-788, 2009.

\section{ORCID}

Rafael Lucas Machado Pinto Juan Carlos Horta Gutiérrez Rodrigo Cardoso Menezes Juan Carlos Campos Rubio Paulo Eustáquio Faria https://orcid.org/0000-0002-0931-9099 https://orcid.org/0000-0002-9010-5310 https://orcid.org/0000-0001-9320-8879 https://orcid.org/0000-0001-6187-6442 https://orcid.org/0000-0002-1987-4379 